\title{
Operative outcomes after laparoscopic splenectomy with special reference to prophylactic antibiotics
}

Tsunemi Matsuda, Shoji Kubo, Masaki Ueno, Katsunari Takifuji, Hiroki Yamaue, Shigekazu Takemura, Shogo Tanaka, Hiroji Shinkawa, Koichi Yamada, Hiroshi Kakeya

\begin{tabular}{|c|l|}
\hline Citation & Asian Journal of Endoscopic Surgery. 12(4); 380-387 \\
\hline Issue Date & $2019-10-22$ \\
\hline Type & Journal Article \\
\hline Textversion & author \\
\hline Rights & $\begin{array}{l}\text { This is the peer reviewed version of the following article: Asian Journal of } \\
\text { Endoscopic Surgery, Vol.12, Issu.4, 380-387., which has been published in final form } \\
\text { at htps://doi.org/10.1111/ases.12661 . This article may be used for non-commercial } \\
\text { purposes in accordance with Wiley Terms and Conditions for Use of Self-Archived } \\
\text { Versions. }\end{array}$ \\
\hline DOI & $10.1111 /$ ASES.12661 \\
\hline
\end{tabular}

Self-Archiving by Author(s) Placed on: Osaka City University

MATSUDA, T., KUBO, S., UENO, M., TAKIFUJI, K., YAMAUE, H., TAKEMURA, S., TANAKA, S., SHINKAWA, H., YAMADA, K., \& KAKEYA, H. (2018). Operative outcomes after laparoscopic splenectomy with special reference to prophylactic antibiotics Splenectomy and prophylactic antibiotics. Asian Journal of Endoscopic Surgery. 12, 380-387. doi:10.1111/ASES.12661 
Original article

Operative outcomes after laparoscopic splenectomy with special reference to prophylactic antibiotics

Tsunemi Matsuda ${ }^{1}$, Shoji Kubo ${ }^{2}$, Masaki Ueno ${ }^{3}$, Katsunari Takifuji ${ }^{3}$, Hiroki Yamaue ${ }^{3}$, Shigekazu Takemura ${ }^{2}$, Shogo Tanaka ${ }^{2}$, Hiroji Shinkawa ${ }^{2}$, Koichi Yamada ${ }^{1}$, Hiroshi Kakeya $^{1}$

${ }^{1}$ Department of Infection Control Science, Osaka City University Graduate School of Medicine

1-4-3 Asahimachi, Abeno-ku, Osaka 545-8585, Japan

2Department of Hepato-Biliary-Pancreatic Surgery, Osaka City University Graduate School of Medicine

1-4-3 Asahimachi, Abeno-ku, Osaka 545-8585, Japan

${ }^{3}$ Second Department of Surgery, School of Medicine, Wakayama Medical University

811-1 Kimiidera, Wakayama, 641-8510, Japan

Running title: Splenectomy and prophylactic antibiotics

Authorship declaration: All authors have contributed to the conception and design (TM, SK, MU, HK), or analysis and interpretation of data (TM, SK, MU, KT, HY, ST, ST, HS, KY, HK), drafting the article (TM, SK, MU) or revising it critically for important intellectual content (HY, HK) and have provided final approval of the version to be published.

Corresponding author: Shoji Kubo, M.D.

Department of Hepato-Biliary-Pancreatic Surgery, Osaka City University Graduate School of Medicine

1-4-3 Asahimachi, Abeno-ku, Osaka 545-8585, Japan

Tel +81-6-6645-3841 Fax +81-6-6646-6057 


\begin{abstract}
Introduction We conducted a retrospective study to investigate the progress of the operative outcome after laparoscopic splenectomy (LS), with a special reference to the administration of prophylactic antibiotics (PA).

Methods The study included 123 patients who underwent elective LS. Operative outcomes before and after the standardization of the operative procedure and the impact of treatment with PA on the surgical site infection (SSI) were investigated.

Results Of the 123 patients, wound infection developed in one (0.8\%), portal trunk thrombosis in one $(0.8 \%)$, pancreatic fistula in one $(0.8 \%)$, postoperative bleeding in two $(1.6 \%)$, pleural effusion in one (0.8\%), and reoperation due to bowel injury in one $(0.8 \%)$. Although morbidity was not different between patients in the early (-2010) and late (2011-) periods, intraoperative blood loss was lower in patients in the late period. During the late period, no patients required conversion to open surgery. The proportion of patients with SSI did not differ between those who received PA $1 \mathrm{~h}$ before the start of the surgery along with additional administration every $3 \mathrm{~h}$ during the surgery and those who received PA $1 \mathrm{~h}$ before the start of the surgery and additional administration during the surgery as well as twice a day for $24-72 \mathrm{~h}$ after the surgery.
\end{abstract}

Conclusion Operative outcomes after LS have improved after the standardization of the operative procedure. The administration of PA $1 \mathrm{~h}$ before the surgery with additional administration of PA every $3 \mathrm{~h}$ during the surgery seems to be sufficient to prevent SSI during LS.

Key words: laparoscopic splenectomy, prophylactic antibiotics, surgical site infection 


\section{Introduction}

The spleen is a fundamental organ for defense against bacterial infection. Splenectomy increases the risk of sepsis, defined as "overwhelming post-splenectomy infection," and is associated with considerable mortality. Patients who require splenectomy include those with hematologic disease or hypersplenism. Therefore, the usefulness of long-term prophylactic antibiotics and vaccination, including pneumococcal vaccination for the prevention of sepsis has been studied resulting in the proposal of guidelines addressing the problem [1 -4].

Since the introduction of laparoscopic splenectomy by Hashizume et al. [5], the surgical procedure has changed from open to laparoscopic splenectomy [6 6 -17]. Postoperative complications following splenectomy include bleeding, surgical site infection (SSI), pancreatic fistula, and portal thrombus. It is well known that the operative outcomes improve with experience of performing laparoscopic surgeries. Kawanaka et al. reported that technical standardization is important to improve the outcome after laparoscopic splenectomy [9].

Although splenectomy is classified as a class I surgical field contamination (clean wound), it has been reported that some patients developed wound infection or subphrenic abscesses [6 -17]. However, details regarding operative outcomes, including SSI, after laparoscopic splenectomy and the effects of prophylactic antibiotics on SSI have not been sufficiently studied. In fact, the methods for the administration of prophylactic antibiotics for SSI after laparoscopic splenectomy have not been evaluated or described in the guidelines for the prevention of SSI, including those of Center for Disease and Prevention (CDC) and World Health Organization (WHO) [18 -20]. Recently, the Japanese Society of Chemotherapy and Japan Society for Surgical Infection advocated practical guidelines for the appropriate use of prophylactic antibiotics [21]. However, there is no evidence regarding the use of prophylactic antibiotics during splenectomy, including laparoscopic splenectomy, in these guidelines.

We conducted a retrospective study to investigate the progress in operative outcomes after elective laparoscopic splenectomy with a special reference to the administration of prophylactic antibiotics.

\section{Materials and Methods}

\section{Patients}

This study included 123 patients who underwent elective laparoscopic splenectomy at the Department of Hepato-Biliary-Pancreatic Surgery, Osaka City University Hospital, or Department of Surgery, Wakayama Medical University Hospital, between 2001 and 
2015. Splenectomy was performed for the following reasons: hypersplenism due to liver cirrhosis caused by hepatitis B or C virus ( $n=93)$; idiopathic hypersplenism ( $n=17)$; splenic tumor, including malignant lymphoma $(n=7)$; immune thrombocytopenia purpura $(\mathrm{n}=4)$; and hereditary spherocytosis $(\mathrm{n}=2)$. Of the 123 patients, 16 underwent hand-assisted laparoscopic splenectomy (HALS) and 107 underwent pure laparoscopic splenectomy (PLS). Gamma-globulin and steroid therapy were administered before surgery in seven and two patients, respectively. Pneumococcal vaccination was administered after splenectomy.

Information concerning clinical findings of the patients, operative procedures, operative outcomes, and administration of prophylactic antibiotics were obtained from the medical records at each hospital.

This study was approved by the ethics committee of Osaka City University and Wakayama Medical University, and was performed according to the Helsinki declaration. All subjects provided written informed consent.

\section{Operative procedures}

Laparoscopic splenectomy was performed under general anesthesia for all patients. The patients were placed in the right lateral decubitus position. In those undergoing HALS, an 8-cm skin incision was made at the upper midline. A camera port was inserted via the umbilicus during HALS or PLS, and two or three ports were inserted approximately 5-7 $\mathrm{cm}$ below the costal margin. After extraction of the liver and stomach, the gastrosplenic ligament was resected using clips. The ligaments and attachments of the spleen, including the splenic flexure of the colon and perisplenic collateral vessels, were dissected using a vessel sealing system such as Harmonic ScalpelTM (Ethicon EndoSurgery Inc., Cincinnati, OH, USA) or LigaSure ${ }^{\mathrm{TM}}$ (Covidien/Metronic Inc. Mansfield, MA, USA). If possible, the splenic artery was identified and ligated in order to decrease the blood supply to the spleen and reduce its volume. After the entire spleen was dissected from the retroperitoneum and the diaphragm, the splenic hilar vessels were divided using the endoscopic linear vascular stapler such as EndGIA ${ }^{\text {TM }}$ (Covidien/Medtronic Inc.) or Echeron ${ }^{\mathrm{TM}}$ (Ethicon Endo-Surgery Inc.). The resected spleen (fragmented spleen in some patients) was extracted in a plastic bag through the middle skin incision (HALS) or umbilical incision (PLS). A Brake Drain (17 or 19 French) with a J-VAC reservoir (Ethicon, Johnson and Johnson, Somerville, NJ, USA) was placed in the subphrenic space. A drain was not used in some patients. In patients with large spleen and/or the presence of large perisplenic collateral vessels, we prepared the conversion from PLS to HALS or open splenectomy. 


\section{Operative outcomes}

To investigate the changes in operative outcomes after laparoscopic splenectomy, the patients were divided into two groups according to the strategy for laparoscopic splenectomy. The PLS or HALS was planned for the first 93 patients (until the end of 2010; the early period), depending on the suspected difficulties, such as large spleen. After the standardization of the operative procedure, PLS was planned for 30 patients (after the beginning of 2011 the late period); the strategy for laparoscopic splenectomy was changed from the beginning of 2011. Operative outcomes were compared between the patients in the early and late periods.

\section{SSI and prophylactic antibiotics}

The duration of the administration of prophylactic antibiotics was shortened based on the increase in the number of patients who underwent laparoscopic splenectomy. Thus, to investigate the impact of treatment with prophylactic antibiotics on SSI, 123 patients were divided into two groups depending on the duration of administration of prophylactic antibiotics: in the long group, prophylactic antibiotics were administered $1 \mathrm{~h}$ before the start of the surgery with additional administration every $3 \mathrm{~h}$ during the surgery and twice a day for 24-72 $\mathrm{h}$ after the surgery $(\mathrm{n}=94)$, whereas in the short group, prophylactic antibiotics were administered $1 \mathrm{~h}$ before the start of the surgery with additional administration every $3 \mathrm{~h}$ during the surgery $(\mathrm{n}=29)$. In both the groups, additional antibiotics were administered every $3 \mathrm{~h}$ during the surgery. For prophylactic antibiotics, cefazolin, cefmetazole, flomoxef, cefotiam, or sulbactum/ampicillin were used. SSI was diagnosed according to the definition of CDC guidelines [18], and was assessed for up to postoperative 30 days.

\section{Statistical analysis}

Continuous variables (age, body mass index, and operation time) were compared using the Student's $t$ test, whereas categorical variables were compared using the Fisher's exact test. The results of the laboratory tests and the amount of intraoperative blood loss were compared using the Mann-Whitney $U$ test. $P$-values $<0.05$ were considered statistically significant.

\section{Results}

\section{Operative outcomes}

A summary of the patients' demographics and intraoperative data are shown in Table 
1. Three of the 107 patients who underwent PLS required conversion to open splenectomy for controlling the intraoperative bleeding. The operation time was $153 \pm$ $64 \mathrm{~min}$, and the intraoperative blood loss was $261 \pm 388 \mathrm{~mL}$. Nine patients received blood (red blood cells) transfusion.

Of the 123 patients, wound infection developed in one (0.8\%), however, the causative bacteria remained unknown. The wound infection improved on opening the wound and orally administrating levofloxacin. Portal trunk thrombosis occurred in one patient $(0.8 \%)$, and the thrombus was dissolved by the administration of urokinase via the superior mesenteric artery, followed by the administration of heparin. Pancreatic fistula developed in one patient $(0.8 \%)$ who then underwent percutaneous abdominal drainage because an abdominal drain was not placed during the surgery. Transcatheter arterial embolization or reoperation was performed due to bleeding from the splenic artery or its branch in two patients $(1.6 \%)$. One patient $(0.8 \%)$ underwent thoracocentasis due to refractory pleural effusion. Reoperation was performed in one patient $(0.8 \%)$ due to bowel injury during splenectomy. Although seven patients underwent invasive treatments (Clavien-Dindo III or greater) for postoperative complications, none died due to postoperative complications.

\section{Changes in operative outcomes}

There were no differences in the patients' age, gender, body mass index, or the proportion of patients with a history of smoking or diabetes mellitus between the early and late periods (Table 1). Other than the platelet count, there were also no difference in the laboratory test results between patients in the early and late periods. Although the platelet count was significantly lower in patients in the early period than in those in the late period, the proportion of patients with thrombocytopenia $\left(<5 \times 10^{4} / \mathrm{mm}^{3}\right) \mathrm{did}$ not differ between the groups. In patients in the early period, 16 underwent HALS and 77 underwent PLS. In three of the 77 patients who underwent PLS, PLS was converted to open splenectomy for controlling the intraoperative bleeding. In the late period, all patients underwent PLS, and none required conversion to open splenectomy. Although the operation time was not different between the groups, the amount of intraoperative blood loss was significantly lower in patients in the late period than in those in the early period. Nine patients in the early period received red blood cell transfusion, whereas none in the late period required transfusion. The incidences of postoperative complications and proportion of patients who underwent invasive treatments were not different between the groups. Thus, in the late group, all patients underwent PLS without conversion or red blood cell transfusion because intraoperative bleeding could 
be controlled.

\section{Prophylactic antibiotics}

The characteristics of patients in the long and short groups according to the duration of administration of prophylactic antibiotics are shown in Table 2. The patients' characteristics did not differ between the groups. The proportion of patients who underwent PLS was significantly higher in the short group than in the long group ( $p=$ 0.0120). Although incisional SSIwound i developed in one of the 94 patients in the long group, it did not occur in any patients in the short group. Organ/space infection did not develop in either group. The proportion of patients with SSI was not significantly different between the two groups. Furthermore, the incidence of postoperative complications other than SSI and proportion of patients who underwent invasive treatments did not differ between the groups.

\section{Discussion}

Postoperative complications after laparoscopic splenectomy included postoperative bleeding, SSI, pancreatic fistula, and portal thrombus. A learning curve is generally important to improve operative outcomes after laparoscopic surgery. In this series, PLS or HALS was planned for the first 93 patients (until the end of 2010; the early period), depending on the suspected difficulties, such as large spleen. After the standardization of the operative procedure, PLS was planned for 30 patients (after the beginning of 2011 the late period). The incidence of postoperative complications and proportion of patients who underwent invasive procedures (Clavien-Dindo III or greater) did not differ between patients in the early and late periods. However, the amount of intraoperative blood loss was significantly lower in patients in the late period than in those in the early period. As a result, no patients in the late period required red blood cell transfusion. In addition, during the late period, no patients required conversion to open surgery because the intraoperative bleeding could be controlled. Although platelet count was significantly lower in patients in the early period than in those in the late period, the proportion of patients with thrombocytopenia, possibly related to intraoperative blood loss, was not different between the groups. The importance of technical standardization of laparoscopic splenectomy has been emphasized [9], and it has been reported to induce a low rate of conversion to open splenectomy and reduced blood loss. Kawanaka et al. [9] reported that the operative procedure was standardized after the experience of 106 patients when their group developed the laparoscopic splenectomy procedure. Therefore, the experience of approximately 100 patients seemed to be necessary to standardize the 
operative procedure and the outcomes after laparoscopic splenectomy improved with an increase in the number of patients who underwent the standardized laparoscopic splenectomy.

After laparoscopic splenectomy for cirrhotic patients who were often associated with hypersplenism and/or portal hypertension, portal or splenic thrombosis occurred in $8.3 \%$ $22 \%[12,14,16,17,22-24]$. In this study, portal trunk thrombosis developed in one patient, and the thrombus was dissolved by the administration of urokinase via the superior mesenteric artery, followed by the administration of heparin. Anticoagulation therapy, such as antithrombin III concentrate and danaparoid sodium, should be considered for the prevention of such thrombosis after laparoscopic splenectomy [21, 22], especially for patients with risk factors for portal thrombus, such as increased splenic vein diameter and low white cell count [25].

In this study, pancreatic fistula developed in one patient $(0.8 \%)$, and postoperative bleeding from the splenic artery or its branch developed in two (1.6\%); the patients were treated with percutaneous abdominal drainage, transcatheter arterial embolization, or reoperation. Pancreatic fistula and postoperative bleeding are serious complications after laparoscopic splenectomy. The prevalence of pancreatic fistula after laparoscopic splenectomy ranged from $2.0 \%-21.7 \%[8,14,16,17,26]$. Careful dissection of the splenic hilum from the pancreas is important to prevent the occurrence of pancreatic fistula and bleeding, especially in patients with splenomegaly [17, 26]. Recently, the usefulness of the combination of fibrin glue and polyglycolic acid felt for the prevention of pancreatic fistula has been reported [17]. When pancreatic fistula develops, close observation of the wound and contents from the abdominal drain and detection of bacteria from the abdominal drain are important. Additionally, antibiotics should be selected according to the bacteria present in the drain contents.

SSI after splenectomy includes the development of incisional SSI and subphrenic abscesses. The incidence of incisional SSI after splenectomy has been reported to range from $4.3 \%$ to $9.8 \%$ and $0 \%$ to $4.8 \%$ in patients who underwent open and laparoscopic splenectomies, respectively [6, 8, 10-17] (Table 3). Winslow et al. [7] reported that subphrenic abscess developed in $2.4 \%$ and $0.1 \%$ of patients who underwent open and laparoscopic splenectomies, respectively. Other studies reported that the incidence of organ/space infection range from $0 \%$ to $6.7 \%$ [6, 8, 10-17]. In this study, incisional SSI developed in one of the 123 patients $(0.8 \%)$, whereas none had organ/space infection. Therefore, the incidence of SSI in this study seems to be comparable or lower than that reported in previous studies.

Although some studies have reported the usefulness of prophylactic antibiotics for 
open splenectomy $[27,28]$, the duration of their use for SSI in patients who underwent laparoscopic splenectomy has not been evaluated. Thus, a practical strategy is needed with regard to the duration of prophylactic antibiotic administration in the clinical setting. Tomikawa et al. [8] reported that incisional SSI occurred in one out of 21 patients (4.8\%) who underwent laparoscopic splenectomy and received prophylactic antibiotics for up to 3 days after the procedure. Wang et al. [14] reported that incisional SSI occurred in $0.3 \%$ of patients who received prophylactic antibiotics for up to 2 days and Yamamoto et al. [16] reported that it occurred in $4.4 \%$ of patients who received prophylactic antibiotics for up to $24 \mathrm{~h}$. In these three studies, organ/space infection did not develop. Migaczewski et al. [11] reported that infective complications occurred in four of 60 patients $(6.7 \%)$ who underwent laparoscopic splenectomy and received prophylactic antibiotics (ceftriaxone) until the first postoperative day. In this study, SSI developed only among patients in the long group in which antibiotics were administered $1 \mathrm{~h}$ before the surgery and 24-72 $\mathrm{h}$ after the surgery. In this study, the proportion of patients who underwent PLS was smaller in the short than in the long group. However, there appeared to be no relationship between SSI and the operative procedure (PLS or HALS) in previous studies. Therefore, the proportion of patients with SSI was not related to the duration of administration of prophylactic antibiotics, and their administration $1 \mathrm{~h}$ before the surgery, followed by additional administration every $3 \mathrm{~h}$ during the surgery seemed to be sufficient for the prevention of SSI in patients who underwent elective laparoscopic splenectomy. The new practical guideline for the appropriate use of prophylactic antibiotics [20] recommend that prophylactic antibiotics should be administered $1 \mathrm{~h}$ before the surgery, with additional administration every $3 \mathrm{~h}$ during the surgery, for splenectomy although there is no evidence regarding the use of prophylactic antibiotics during splenectomy. The results in this study support the recommendation.

The study had several limitations. This was a retrospective study with a small sample size; therefore we could not reach definitive conclusions. Retrospective and prospective studies including a larger number of patients are necessary to evaluate the progress in postoperative outcomes and duration of prophylactic antibiotic administration. However, the number of patients who underwent laparoscopic splenectomy was originally small. The proportion of patients with SSI was originally small in patients who underwent laparoscopic splenectomy. In addition, conducting such studies is challenging because advances in antiviral treatments for chronic hepatitis B and $\mathrm{C}$, including direct acting agents, has decreased the number of patients requiring splenectomy. Thus, it is impossible to obtain a definitive conclusion about the duration of prophylactic antibiotic administration, because a very large number of patients would be necessary. Although 
the statistical analysis was insufficient, the results of this study provide a practical strategy that can be applied in the clinical setting.

In conclusion, outcomes after laparoscopic splenectomy have improved with an increase in experience. The administration of antibiotics $1 \mathrm{~h}$ before the surgery, with additional administration of prophylactic antibiotics every $3 \mathrm{~h}$ during the surgery, seems to be sufficient to prevent SSI during laparoscopic splenectomy.

Acknowledgement: The authors thank Enago (www.wnago.jp) for English language review.

Conflict of interest: We have no conflicts of interest to declare

References

1. Mangram AJ, Horan TC, Pearson ML, Silver LC, Jarvis WR. Guideline for prevention of surgical site infection, 1999. Centers for Disease Control and Prevention (CDC) Hospital Infection Control Practices Advisory Committee. Am J Infect Control 1999; 27: 97-132.

2. Solomkin JS, Mazuski JE, Baron EJ, et al. Infectious Diseases Society of America. Guidelines for the selection of anti-infective agents for complicated intra-abdominal infections. Clin Infect Dis 2003; 27: 997-1005.

3. Melles DC, de Matie S. Prevention of infections in hyposplenic and asplenic patients: an update. Netherlands J Med 2004; 62: 45-51.

4. Davies JM, Lewis MP, Wimperis J, Rafi I, Ladhani S, Bolton-Maggs PH; British Committee for Standards in Haematology. Review of guidelines for the prevention and treatment of infection in patients with an absent or dysfunctional spleen: prepared on behalf of the British Committee for Standards in Haematology by a Working Party of the Haemato-Oncology Task Force. Brit J Haematology 2011; 155; 308-317.

5. Hashizume, Sugimachi K, Ueno K. Laparoscopic splenectomy with an ultrasonic dissector. N Engl J Med 1992; 327: 438.

6. Tanoue K, Hashizume M, Morita M, et al. Results of laparoscopic splenectomy for immune thrombocytopenic purpura. Am J Surg 1999; 177: 222-226.

7. Winslow ER, Brunt LM. Perioperative outcomes of laparoscopic versus open splenectomy: a meta-analysis with an emphasis on complications. Surgery 2003; 134: 647-655.

8. Tomikawa M, Akahoshi T, Sugimachi K, et al. Laparoscopic splenectomy may be a 
superior supportive intervention for cirrhotic patients with hypersplenism. J Gastroenterol Hepatol 2010; 25: 397-402.

9. Kawanaka H, Akahoshi T, Kinjo N, et al. Technical standardization of laparoscopic splenectomy harmonized with hand-assisted laparoscopic surgery for patients with liver cirrhosis and hypersplenism. J Hepatobiliary Pancreat Surg 2009; 16: 749-757.

10. Casaccia M, Torelli P, Pasa A, et al. Putative predictive parameters for the outcome of laparoscopic splenectomy: a multicenter analysis performed on the Italian registry of laparoscopic surgery of the spleen. Ann Surg 2010; 251: 287-291.

11. Migaczewski M, Zub-Pokrowiecka A, Budzyński P, Matłok M, Budzyński A. Prevention of early infective complications after laparoscopic splenectomy with the Garamycin sponge. Videosurgery Miniinv 2012; 7: 105-110.

12. Bulus H, Mahmoud H, Altun H, Tas A, Karayalcin K. Outcomes of laparoscopic versus open splenectomy. J Koreon Surg Soc 2014; 82: 38-42.

13. Corcione F, Pirozzi F, Aragiuto G, Galante F, Sciuto A. Laparoscopic splenectomy: experience of a single center in a series of 300 cases. Surg Endosc 2012; 26: 28702876.

14. Wang X, Li Y, Crook N, Peng B, Niu T. Laparoscopic splenectomy: a surgeon's of 302 patients with analysis of postoperative complications. Surg Endosc 2013; 27: 35643571.

15. Li B, Liu J, Shangguan Y, Liu B, Qi Y. Laparoscopy-assisted small incision splenectomy and open splenectomy in the treatment of hematologic diseases: a single-institution comparative experience. Surg Laparosc Endosc Percutan Tech 2013; 23: 309-311

16. Yamamoto N, Okano K, Oshima M, et al. Laparoscopic splenectomy for patients with liver cirrhosis: improvement of liver function in patients with Child-Pugh class B. Surgery 2015; 158: 1538-1544.

17. Tsutsumi N, Tomikawa M, Akahoshi T, et al. Pancreatic fistula after laparoscopic splenectomy in patients with hypersplenism due to liver cirrhosis: effect of fibrin glue and polyglycolic acid felt on prophylaxis of postoperative complications. Am J Surg 2016; 212: 882-888.

18. Mangram AJ HT, Pearson ML, Silver LC, Jarvis WR. Guideline for prevention of surgical site infection, 1999. Infect Control Hosp Epidemiol 1999; 20: 250-278.

19. Berríos-Torres SI, Umscheid CA, Bratzler DW, et al. Centers for Disease Control and Prevention guideline for the prevention of surgical site infection, 2017 JAMA Surg 2017; 152: 784-791.

20. World Health Organization. Global guidelines for the prevention of surgical site 
infection. http://www.who.int/gpsc/en/

21. Guideline committee for practical guidelines for the appropriate use of prophylactic antibiotics: Japanese Society of Chemotherapy and Japan Society for Surgical Infection. Practical guidelines for the appropriate use of prophylactic antibiotics. www.chemotherapy.or.jp/guideline/jyutsugo_shiyou_jissen.pdf

22. Kawanaka H, Akahoshi T, Kinjo N, et al. Impact of antithrombin III concentrates on portal vein thrombosis after splenectomy in patients with liver cirrhosis and hypersplenism. Ann Surg 2010; 251: 76-83.

23. Kawanaka H, Akahoshi T, Itoh S, et al. Optimizing risk stratification in portal vein thrombosis after splenectomy and its primary prophylaxis with antithrombin III concentrates and danaparoid sodium in liver cirrhosis with portal hypertension. $\mathrm{J}$ Am Coll Surg 2014; 219: 865-874.

24. Wang M, Wei A, Zhang Z, Peng B. Laparoscopic splenectomy for the elderly liver cirrhotic patients with hypersplenism. Medicine 2016; 95: e3012

25. Kinjo N, Kawanaka H, Akahoshi T, et al. Risk factors for portal venous thrombosis after splenectomy in patients with cirrhosis and portal hypertension. Br J Surg 2010; 97: 910-916.

26. Chard B, Walsh RM, Ponsky J, Brodt F. Pancreatic complications following laparoscopic splenectomy. Surg Endosc 2001; 15: 1273-1276.

27. Mozzill N, Greci S, Perscini A, Formato A. Chemoprophylaxis in the surgical ward: results of a national survey in Italy. Eur J Epidemiol 1988; 4: 357-359.

28. Koratzanis G, Giamarellos-Bourboulis EJ, Papalambros E, Giamarellou H. Bacterial translocation following intraabdominal surgery. Any influence of antimicrobial prophylaxis? Int J Antimicrobial Agents 2002; 20: 457-460. 
Table 1 Changes in operative outcomes in the early (up to 2010) and late (from 2011) periods

\begin{tabular}{|c|c|c|c|c|}
\hline & $\begin{array}{l}\text { All subjects } \\
(n=123)\end{array}$ & $\begin{array}{l}\text { Early period } \\
(n=93)\end{array}$ & $\begin{array}{l}\text { Late period } \\
(\mathrm{n}=30)\end{array}$ & $P$-value \\
\hline Age & $59.5 \pm 11.8$ & $60.4 \pm 9.4$ & $56.4 \pm 17.0$ & 0.0652 \\
\hline Gender (M:F) & $48: 75$ & $38: 55$ & $10: 20$ & 0.523 \\
\hline Body mass index & $23.2 \pm 4.6$ & $23.5 \pm 4.2$ & $22.2 \pm 5.8$ & 0.220 \\
\hline Smoking & 15 & 10 & 5 & 0.521 \\
\hline Diabetes mellitus & 25 & 17 & 8 & 0.312 \\
\hline White blood cell (per $\mathrm{mm}^{3}$ ) & $2900(1700,5620)$ & $3020(1610,5960)$ & $3310(1880,6200)$ & 0.371 \\
\hline Hemoglobin (g/dL) & $12.3(10.2,14.6)$ & $11.9(10.1,13.7)$ & $12.0(10.1,13.6)$ & 0.0903 \\
\hline Platelet $\left(\times 10^{4} / \mathrm{mm}^{3}\right)$ & $5.0(2.8,7.5)$ & $4.9(2.7,6.8)$ & $5.6(3.3,16.6)$ & 0.0258 \\
\hline Thrombocytopenia $\left(\left\langle 5 \times 10^{4} / \mathrm{mm}^{3}\right)\right.$ & 60 & 49 & 11 & 0.146 \\
\hline PT-INR & $1.16(1.01,1.29)$ & $1.16(1.01,1.29)$ & $1.16(0.95,1.29)$ & 0.616 \\
\hline Total bilirubin (mg/dL) & $1.2(0.5,2.1)$ & $1.3(0.5,2.2)$ & $1.1(0.4,2.0)$ & 0.141 \\
\hline Albumin (g/dL) & $3.7(3.1,4.3)$ & $3.5(3.0,4.5)$ & $3.7(3.0,4.5)$ & 0.401 \\
\hline HALS:PLS & 16:107 & $16: 77$ & $0: 30$ & 0.0115 \\
\hline Operation time $(\mathrm{min})$ & $153 \pm 64$ & $150 \pm 61$ & $162 \pm 74$ & 0.0903 \\
\hline Intraoperative blood loss (mL) & $75(5,735)$ & $100(5,990)$ & $68(5,300)$ & 0.0403 \\
\hline Red blood cell transfusion & 9 & 9 & 0 & 0.111 \\
\hline Conversion to open surgery & 3 & 3 & 0 & $>0.999$ \\
\hline \multicolumn{5}{|l|}{ Prophylactic antibiotics } \\
\hline Long group:short group & $94: 29$ & $86: 7$ & $8: 22$ & $<0.001$ \\
\hline \multicolumn{5}{|l|}{ Postoperative complications } \\
\hline Bowel injury during operation & 1 & 1 & 0 & $>0.999$ \\
\hline Wound infection & 1 & 1 & 0 & $>0.999$ \\
\hline Organ/space infection & 0 & 0 & 0 & $>0.999$ \\
\hline Portal or splenic vein thrombus & 1 & 0 & 1 & 0.244 \\
\hline Postoperative bleeding & 2 & 1 & 1 & 0.244 \\
\hline Pancreatic fistula & 1 & 0 & 1 & 0.244 \\
\hline $\begin{array}{l}\text { Refractory pleural effusion or } \\
\text { ascites }\end{array}$ & 1 & 0 & 1 & 0.238 \\
\hline Ileus & 1 & 1 & 0 & $>0.999$ \\
\hline Clavien-Dindo III or greater & 7 & 3 & 4 & 0.0595 \\
\hline
\end{tabular}

Age, body mass index, and operation time are presented as the mean \pm standard deviation.

Laboratory test results and blood loss are presented as median (10th, 90th percentiles).

Numbers represent the number of patients.

Abbreviations: ASA, American Society of Anesthesiologists physical status classification;

HALS, hand-assited laparoscopic splenectomy; ITP, idiopathic hypersplenism;

PLS, pure laparoscopic splenectomy; PT-INR, prothrombin time-international normalized ratio. 
Table 2 Clinical findings in patients who underwent laparoscopic splenectomy with different durations of prophylactic antibiotic admistration

\begin{tabular}{|c|c|c|c|}
\hline & $\begin{array}{l}\text { Short group } \\
(n=29)\end{array}$ & $\begin{array}{l}\text { Long group } \\
(n=94)\end{array}$ & $P$-value \\
\hline$\overline{\text { Age }}$ & $56.3 \pm 17.1$ & $60.6 \pm 9.0$ & 0.0660 \\
\hline Gender (M:F) & $11: 18$ & $37: 57$ & $>0.999$ \\
\hline Disease (hypersplenism, IPH) & 22 & 88 & 0.0125 \\
\hline Body mass index & $23.8 \pm 4.1$ & $23.2 \pm 4.2$ & 0.220 \\
\hline Smoking & 3 & 12 & $>0.999$ \\
\hline Diabetes mellitus & 6 & 19 & $>0.999$ \\
\hline White blood cell (per $\mathrm{mm}^{3}$ ) & $3020(1610,5960)$ & $2850(1800,4900)$ & 0.208 \\
\hline Hemoglobin $(\mathrm{g} / \mathrm{dL})$ & $11.9(10.1,13.7)$ & $12.4(10.6,14.8)$ & 0.0427 \\
\hline Platelet $\left(\times 10^{4} / \mathrm{mm}^{3}\right)$ & $5.5(2.8,11.1)$ & $4.9(2.9,7.2)$ & 0.135 \\
\hline PT-INR & $1.16(1.01,1.29)$ & $1.17(1.02,1.3)$ & 0.863 \\
\hline Total bilirubin $(\mathrm{mg} / \mathrm{dL})$ & $1.3(0.5,2.2)$ & $1.2(0.6,2.0)$ & 0.747 \\
\hline Albumin $(\mathrm{g} / \mathrm{dL})$ & $3.5(3.0,4.5)$ & $3.7(3.1,4.3)$ & 0.641 \\
\hline HALS:PLS & $0: 29$ & $16: 78$ & 0.0123 \\
\hline Operation time (min) & $133 \pm 56$ & $158 \pm 65$ & 0.0683 \\
\hline Intraoperative blood loss $(\mathrm{mL})$ & $56(5,400)$ & $100(10,950)$ & 0.132 \\
\hline Red blood cell transfusion & 1 & 8 & 0.684 \\
\hline \multicolumn{4}{|l|}{ Postoperative complications } \\
\hline Bowel injury during operation & 0 & 1 & $>0.999$ \\
\hline Wound infection & 0 & 1 & $>0.999$ \\
\hline Organ/space infection & 0 & 0 & $>0.999$ \\
\hline Portal or splenic vein thrombus & 0 & 1 & $>0.999$ \\
\hline Postoperative bleeding & 1 & 1 & 0.417 \\
\hline Pancreatic fistula & 1 & 0 & 0.236 \\
\hline $\begin{array}{l}\text { Refractory pleural effusion or } \\
\text { ascites }\end{array}$ & 1 & 0 & 0.236 \\
\hline Ileus & 0 & 1 & $>0.999$ \\
\hline Clavien-Dindo III or greater & 3 & 4 & 0.354 \\
\hline
\end{tabular}

Age, body mass index, and operation time are presented as the mean \pm standard deviation.

Laboratory test results and blood loss are presented as the median (10th, 90th percentiles).

Numbers represent the number of patients.

Abbreviations: ASA, American Society of Anesthesiologists physical status classification;

HALS, hand-assited laparoscopic splenectomy; ITP, idiopathic hypersplenism;

PLS, pure laparoscopic splenectomy; PT-INR, prothrombin time-international normalized ratio 
Table 3 Surgical site infection and prophylactic antibiotics in laparoscopic splenectomy

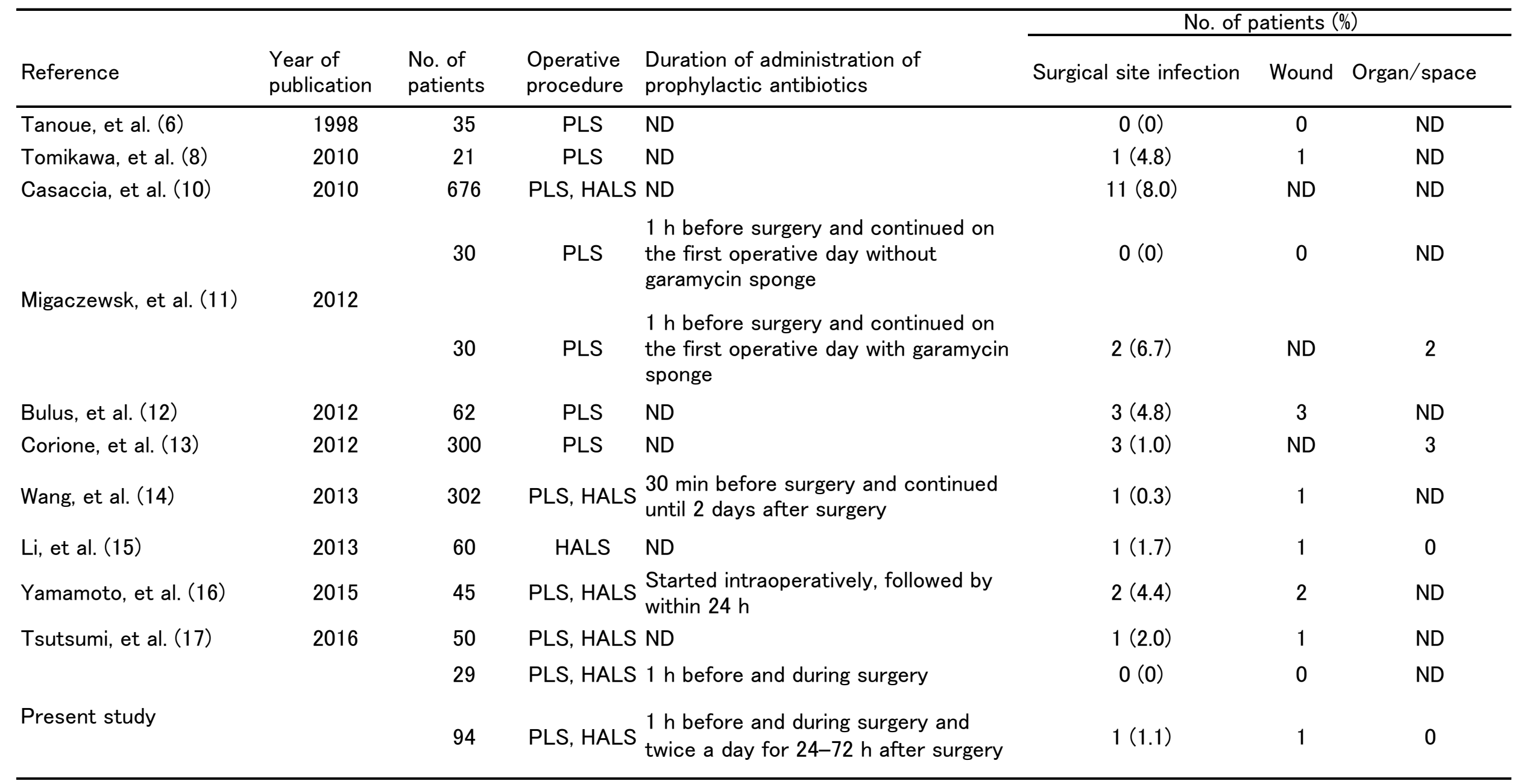

Abbreviations: PLS, pure laparoscopic splenectomy; HALS, hand-assited laparoscopic splenectomy; ND, not described 